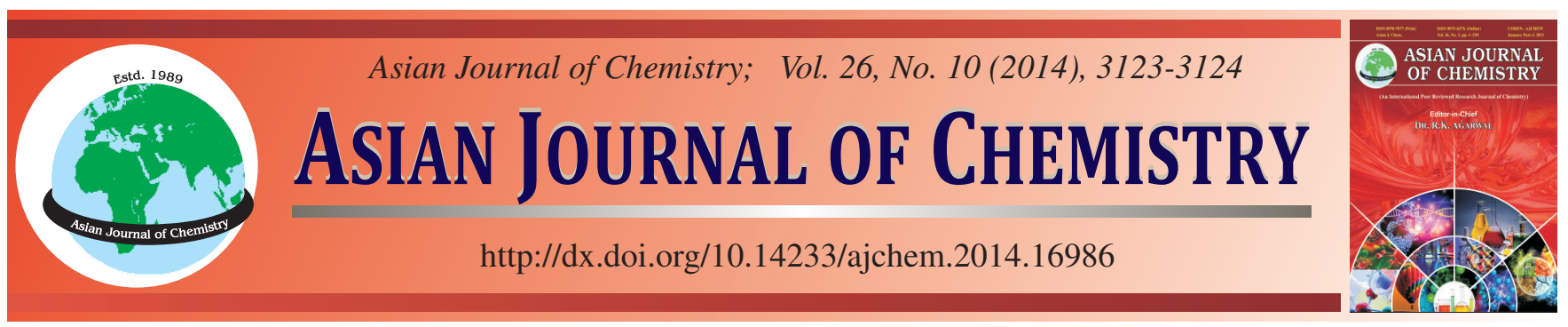

NOTE

\title{
Synthesis and Crystal Structure of Novel 4-6-connected Co(II) Coordination Polymers Constructed by Pyridinedicarboxylate and Imidazole-Containing Ligands
}

\author{
Guanglong Zou ${ }^{1, *}$, Xuelin Wang ${ }^{2}$, Tingting $\mathrm{Li}^{1}$, Zhiqing FAng ${ }^{1}$ and Bing Xie ${ }^{1, *}$
}

${ }^{1}$ School of Chemistry and Enviromental Science, Guizhou Minzu Univeristy, Guiyang 550025, P.R. China

${ }^{2}$ School of Science, Guizhou Minzu University, Guiyang 550025, P.R. China

*Corresponding authors: E-mail: scesgzmu@126.com

Received: 6 January 2014;

Accepted: 13 February 2014;

Published online: 10 May 2014;

AJC-15195

A new coordination polymers $\left.\left\{\mathrm{Co}(2,3-\mathrm{PDC})(\mathrm{bib})_{1.5}\right] \cdot 3 \mathrm{H}_{2} \mathrm{O}\right\}_{\mathrm{n}}(\mathbf{1})$ [2,3-PDC $=2,3$-pyridine dicarboxylic acid and bib=1,4-bis $(\mathrm{imidazol}-1$ yl)benzene] has been prepared by hydrothermal synthesis. Complex $\left.\left\{\mathrm{Co}(2,3-\mathrm{PDC})(\mathrm{bib})_{1.5}\right] \cdot 3 \mathrm{H}_{2} \mathrm{O}\right\}_{\mathrm{n}}(\mathbf{1})$, is triclinic, space group $\mathrm{P}-1$ with $\mathrm{a}=9.666(5) \AA, \mathrm{b}=11.358(5) \AA, \mathrm{c}=13.671(5) \AA, \alpha=69.701(5)^{\circ}, \beta=70.792(5)^{\circ}, \gamma=81.688(5)^{\circ}, \mathrm{V}=1328.5(10) \AA^{3}, \mathrm{Z}=2, \mathrm{Mr}=$ $593.44, D_{c}=1.484 \mathrm{~g} / \mathrm{cm}^{3}, \mathrm{~F}(000)=612$ and $\mu=0.70 \mathrm{~mm}^{-1}$. The final refinement gave $\mathrm{R}=0.0533$ and $w \mathrm{R}=0.0584$ for 5142 reflections with $\mathrm{I}>2 \sigma(\mathrm{I})$. X-ray diffraction analysis reveals that complex 1 shows a $(4,6)$-connected three-dimensional (3D) structure with the point symbol $\left(4^{4} \cdot 6^{2}\right) \cdot\left(4^{8} \cdot 6^{7}\right)$.

Keywords: Coordination polymer, Co (II), Crystal structure, Metal-organic framework.

Over the past decade, there has been much interest in the fabrication of metal-organic frameworks (MOFs) due to their novel architectures and potential applications ${ }^{1-8}$. Recently, more and more nitrogen-containing ligands have been employed to construct coordination polymers with fascinating architectures and interesting properties ${ }^{9-11}$. Metal-organic frameworks constructed from rigid bidentate 1,4-bis(1-imidazol-yl)-2,5dimethyl benzene ligands are relatively scarce ${ }^{12-14}$. The results of our previous studies show that this rigid neutral bis(imidazole) ligand exhibits the special ability to coordinate to various metal centers. However, the organic polycarboxylic acids ligands, which are the most efficient organic ligands to connect different metal ions, including main-group metals, transition metals and rare-earth metals, have been extensively employed to construct metal-organic frameworks with diversity structures ${ }^{15,16}$.

In this paper, we successfully synthesized a new $\mathrm{Co}$ (II) coordination polymer based on 2,5-pyridinedicarboxylic acid and 1,4-bis(1-imidazol-yl)-2,5-dimethyl benzene. The complex 1 show a rare $(4,6)$-connected three-dimensional(3D) structure with the $\left(4^{4} \cdot 6^{2}\right) \cdot\left(4^{8} \cdot 6^{7}\right)$ point symbol.

All reagents and solvents employed were commercially available and used without further purification. Elemental analysis was carried out on a Carlo Erba 1106 full-automatic trace organic elemental analyzer. FT-IR spectra were recorded with a Bruker Equinox 55 FT-IR spectrometer as a dry $\mathrm{KBr}$ pellet in the $4000-400 \mathrm{~cm}^{-1}$ range.

\section{Synthesis}

Synthesis of $\left.\left\{\mathrm{Co}(\mathbf{2 , 3}-\mathrm{PDC})(\mathrm{bib})_{1.5}\right] \cdot \mathbf{3} \mathrm{H}_{\mathbf{2}} \mathrm{O}\right\}_{\mathrm{n}}$ (1): The mixtures of $\mathrm{CoCl}_{2} \cdot 6 \mathrm{H}_{2} \mathrm{O}(0.5 \mathrm{mmol}, 0.119 \mathrm{~g})$, 2,3-pyridine dicarboxylic acid (0.5 mmol, $0.084 \mathrm{~g})$, 1,4-bis(imidazol-1yl)benzene ( $0.5 \mathrm{mmol}, 0.119 \mathrm{~g}), \mathrm{NaOH}$ (1mmol, $0.04 \mathrm{~g}$ ) and $12 \mathrm{~mL}$ of water were heated to $140{ }^{\circ} \mathrm{C}$ for 4 days and then cooled to room-temperature. The red crystals were obtained in pure phase, washed with water and ethanol and dried at room temperature (Yield: $46 \%$ based on Co). Elemental analysis calcd. (\%) for $\mathrm{C}_{25} \mathrm{H}_{24} \mathrm{~N}_{7} \mathrm{O}_{7} \mathrm{Co}$ : C, 50.60; $\mathrm{H}, 4.08 ; \mathrm{N}$, 16.52. Found: C, 50.62; H,4.09; N, 16.53; IR $\left(\mathrm{KBr}, \mathrm{cm}^{-1}\right): 1612$ s, $1507 \mathrm{~m}, 1423 \mathrm{~m}, 1383 \mathrm{~m}, 1271 \mathrm{~m}, 1055 \mathrm{~m}, 967 \mathrm{~m}, 807 \mathrm{~m}$, $733 \mathrm{~m}, 658 \mathrm{~m}$.

X-ray crystallography: Single crystal X-ray diffraction analyses of complex 1 was carried out on a Bruker SMART APEXII CCD diffractometer equipped with a graphite monochromated $\mathrm{MoK}_{\alpha}$ radiation $(\lambda=0.71073 \AA$ ) by using a $\omega$-scan mode. Empirical absorption correction was applied using the SADABS programs ${ }^{17}$. All the structures were solved by direct methods and refined by full-matrix least-squares methods on $\mathrm{F}^{2}$ using the program SHEXL $97^{18}$. All non-hydrogen atoms were refined anisotropically. The hydrogen atoms were located by geometrically calculations and their positions and thermal parameters were fixed during the structure refinement. The selected bond lengths and angles are listed in Table-1. 


\begin{tabular}{|c|c|c|c|}
\hline \multicolumn{4}{|c|}{$\begin{array}{c}\text { TABLE-1 } \\
\text { SELECTED BOND LENGTHS (Å) } \\
\text { AND ANGLES }\left({ }^{\circ}\right) \text { FOR COMPLEX } 1\end{array}$} \\
\hline \multicolumn{4}{|c|}{ Complex 1} \\
\hline $\mathrm{Co}(1)-\mathrm{O}(1)$ & $2.131(2)$ & $\mathrm{Co}(1)-\mathrm{N}(3)$ & $2.164(2)$ \\
\hline $\mathrm{Co}(1)-\mathrm{O}(1)$ & $2.131(2)$ & $\mathrm{Co}(2)-\mathrm{O}(4)$ & $2.058(2)$ \\
\hline $\mathrm{Co}(2)-\mathrm{N}(5)$ & $2.124(3)$ & $\mathrm{Co}(2)-\mathrm{N}(6)$ & $2.187(3)$ \\
\hline $\mathrm{O} 1-\mathrm{Co} 1-\mathrm{N} 3$ & $85.48(9)$ & $\mathrm{O} 1-\mathrm{Co} 1-\mathrm{N} 1$ & $86.63(9)$ \\
\hline $\mathrm{N} 1-\mathrm{Co} 1-\mathrm{N} 3$ & $93.53(9)$ & $\mathrm{O} 4-\mathrm{Co} 2-\mathrm{N} 5$ & $101.84(9)$ \\
\hline $\mathrm{O} 4-\mathrm{Co} 2-\mathrm{N} 6$ & $90.60(10)$ & $\mathrm{N} 5-\mathrm{Co} 2-\mathrm{N} 6$ & $92.29(10)$ \\
\hline
\end{tabular}

The X-ray single analysis study of complex 1 shows that the complex 1 crystallizes in triclinic P-1 space group. As shown in Fig. 1, the asymmetric unit of $\mathbf{1}$ contains two crystallographically unique $\mathrm{Co}(\mathrm{II})$ ions, two 2,3-pyridine dicarboxylic acid ligands, two 1,4-bis(imidazol-1-yl)benzene ligands and three lattice water . Two Co(II) centers are in different coordination geometries. The Co1 locates in an octahedral geometry, completed by two carboxylate oxygen atoms and four nitrogen atoms from bib ligands. The $\mathrm{Co} 2$ also shows the $\mathrm{CoO}_{2} \mathrm{~N}_{4}$ octahedral geometry but completed by two carboxylate oxygen atoms, two pyridine nitrogen and two nitrogen from bib ligands. The Co-O/N bond lengths are in the range 2.058 (2)-2.187 (3) A. The Co ions are connected by carboxylate ligands to a $1 \mathrm{D}$ neutral chain (Fig. 2). The 1,4-bis(imidazol-1-yl)benzene ligands connect $1 \mathrm{D}$ chains to form a 3D structure.

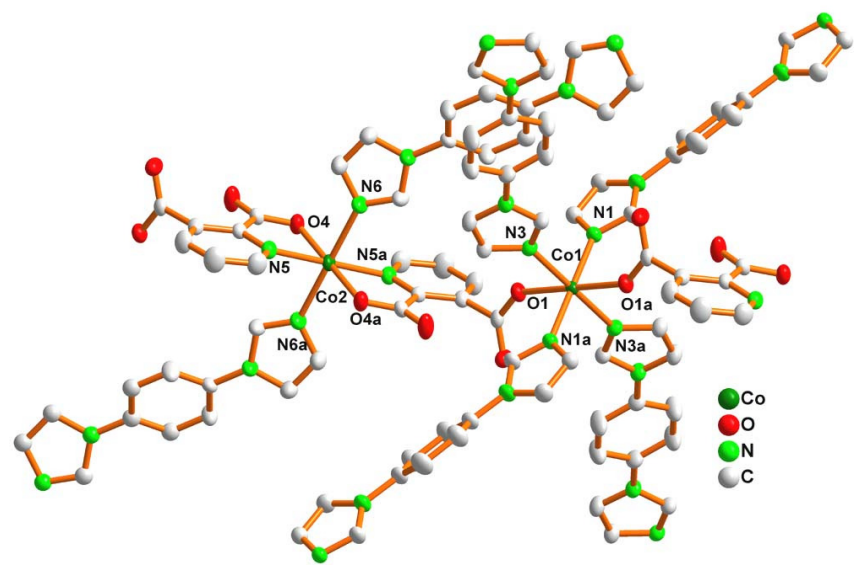

Fig. 1. Coordination environment for $\mathrm{Co}(\mathrm{II})$ ion

In order to understand the structure of the complex, topological analysis was performed on complex $\mathbf{1}$. The Co1 and $\mathrm{Co} 2$ are simplified as 6-connected node and 4-connected node, respectively. The organic ligands are considered as connectors, this structure can be described as a bimodal $(4,6)$-connected net with point symbol of $\left(4^{4} \cdot 6^{2}\right) \cdot\left(4^{8} \cdot 6^{7}\right)$ (Fig. 3$)$.

\section{ACKNOWLEDGEMENTS}

The authors gratefully acknowledge the financial support of Scientific Research Foundation of Guizhou Minzu Univeristy (GZMU-201301) and Joint Foundation between GZST and GZMU (LKM201305) and Natural Science Foundation of China (No. 21363004 and 21362005).

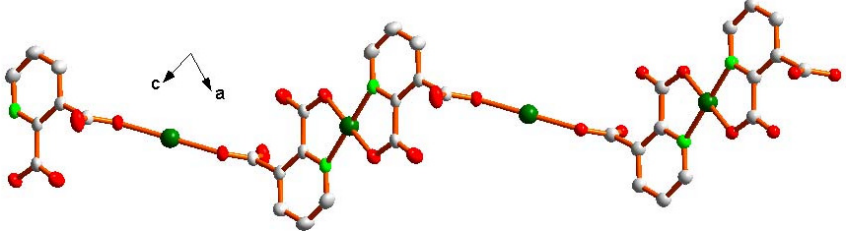

Fig. 2. One-dimensional chain for complex 1

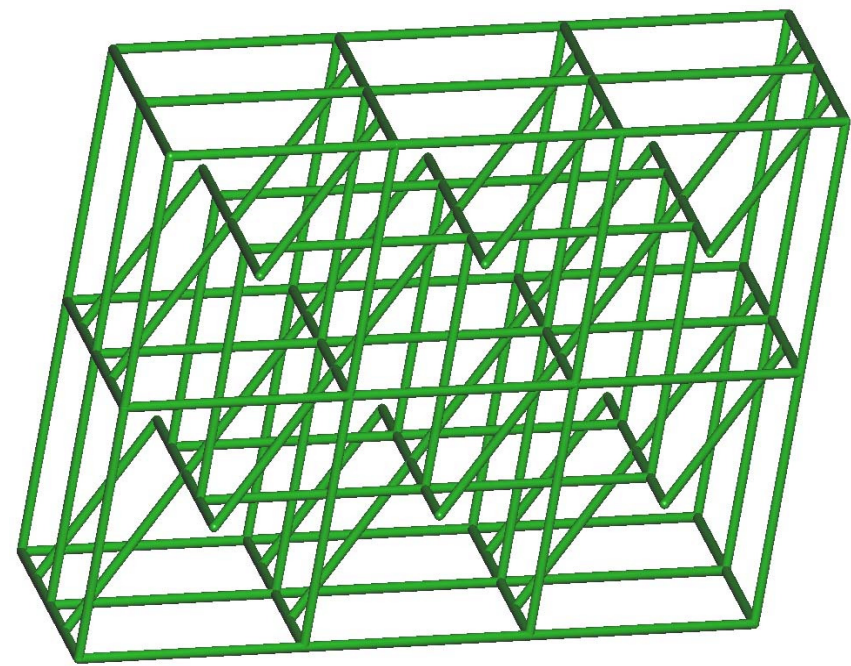

Fig. 3. Topological net for complex 1

\section{REFERENCES}

1. J.L.C. Rowsell and O.M. Yaghi, Angew. Chem. Int. Ed., 44, 4670 (2005).

2. X.L. Wang, C. Qin, E.B. Wang, L. Xu, Z.M. Su and C.W. Hu, Angew. Chem. Int. Ed., 43, 5036 (2004).

3. S. Kitagawa, R. Kitaura and S.I. Noro, Angew. Chem. Int. Ed., 43, 2334 (2004).

4. M. Eddaoudi, J. Kim, N.L. Rosi, D.T. Vodak, J. Wachter, M. O'Keeffe and O.M. Yaghi, Science, 295, 469 (2002).

5. K. Sumida, S. Horike, S.S. Kaye, Z.R. Herm, W.L. Queen, C.M. Brown, F. Grandjean, G.J. Long, A. Dailly and J.R. Long, Chem. Sci., 1, 184 (2010).

6. S.-C. Xie, Asian J. Chem., 25, 3529 (2013).

7. Z.Q. Jiang, Asian J. Chem., 25, 2353 (2013).

8. Y.-P. Hu, C.-P. Tan, S.-F. Wang and X.-B. Meng, Asian J. Chem., 25, 1137 (2013).

9. K. Biradha, C. Seward and M.J. Zaworotko, Angew. Chem. Int. Ed., 38, 492 (1999).

10. Y. Akkaya, S. Akyuz and T. Akyuz, Asian J. Chem., 25, 9185 (2013).

11. S.H. Cho, B.Q. Ma, S.T. Nguyen, J.T. Hupp and T.E. Albrecht-Schmitt, Chem. Commun., 2563 (2006).

12. K.S. Suslick, P. Bhyrappa, J.H. Chou, M.E. Kosal, S. Nakagaki, D.W. Smithenry and S.R. Wilson, Acc. Chem. Res., 38, 283 (2005).

13. M.D. Allendorf, C.A. Bauer, R.K. Bhakta and R.J.T. Houk, Chem. Soc. Rev., 38, 1330 (2009).

14. E.Y. Lee, S.Y. Jang and M.P. Suh, J. Am. Chem. Soc., 127, 6374 (2005).

15. J. Yang, G.D. Li, J.J. Cao, Q. Yue, G.H. Li and J.S. Chen, Eur. Chem. J., 13, 3248 (2007).

16. C. Janiak and J.K. Vieth, New J. Chem., 34, 2366 (2010).

17. A.X.S. Bruker, SAINT Software Reference Manual, Madison, WI, (1998).

18. G.M. Sheldrick, SHELXTL NT Version 5.1. Program for Solution and Refinement of Crystal Structures, University of Göttingen, Germany, (1997). 